\title{
Study of the inclusion of yeasts in the ruminal fermentation of Tifton hay
}

\author{
Yoandra Marrero Rodríguez ${ }^{\mathrm{a}}$, Ronaldo Carlos Lucas ${ }^{\mathrm{b}}$, Maria Regina Santos Rodeiro Pecanha ${ }^{\mathrm{b}}$, \\ Adibe Luiz Abdallab ${ }^{\text {, Niurca Gonzalez Ibarrac }}$ \\ ${ }^{a}$ National Center for the Production of Laboratory Animals, La Habana, Cuba. \\ ${ }^{b}$ Animal Nutrition Laboratory. Center for Nuclear Energy in Agriculture (CENA), University of São Paulo, Piracicaba, Brazil. \\ Institute of Animal Science (ICA), Mayabeque, Cuba.
}

\begin{abstract}
This study aimed to evaluate, under in vitro conditions, the effect of the inclusion of yeasts of different species on some fermentation parameters of Tifton hay. The gas production technique was used and the strains evaluated belong to the species: Rhodotorula mucilaginosa, Issatchenkia orientalis, Candida tropicalis, Pichia guilliermondii, and Saccharomyces cereviasiae. The equivalent of $7.0 \mathrm{mg}$ DM of yeasts was added and the presence of living cells in them was in the order of $10^{7}$ cells . $\mathrm{mL}^{-1}$. The parameters under study were: accumulated gas production, methane, ammoniacal nitrogen concentration and protozoan count. Only the $I$. orientalis and $S$. cereviasiae strains stimulated gas production and the inclusion of yeasts did not show an effect on the rest of the parameters under study. It is concluded that the species and strain of yeast have a decisive effect on the ruminal fermentation of fibrous substrates, which reaffirms the importance of selecting the appropriate strains for being used as an additive in ruminant diets, according to the food you want to use.
\end{abstract}

KEYWORDS: Candida; gas production; Issatchenkia; Pichia; Rhodotorula; Saccharomyces

Accepted September 23, $2021 \quad$ Published online November 25, 2021

Cite this article: Rodríguez et al. (2021) Study of the inclusion of yeasts in the ruminal fermentation of Tifton hay. Multidisciplinary Science Journal 3: e2021020, doi:10.29327/multiscience.2021020.

\section{Introduction}

The addition of yeasts to the diet of ruminant animals has favorable effects on the microbial population and the fermentation indicators of the rumen and consequently, improves the productivity of the animals (Elghandour et al 2014). It also constitutes a replacement alternative to the use of growth-promoting antibiotics (Tripathi and Karim 2011).

In the world market, there are multiple products that use commercial strains of Saccharomyces cerevisiae yeast as ruminal fermentation activators (Chaucheyras et al 2012). However, there are not many studies that show the use of other yeast genera for these purposes. Thus, Castillo et al (2016) found that the yeast strain Issatchenkia orientalis could be a potential candidate for being used as an additive. Wang et al (2016) also studied the inclusion of strains from Candida genus under in vitro conditions and showed the positive effect of Candida tropicalis on ruminal fermentation. On the other hand, Marrero et al (2020), in studies carried out in Cuba and Mexico, respectively, showed that yeast strains of several species showed greater stimulation of the in vitro gas production of Cynodon nlemfuensis when compared with a strain of $S$. cerevisiae and that the species and strain of yeasts, as well as their inclusion dose, had a determining effect on the in vitro gas production from different fibrous substrates.

There are different hypotheses about the action mechanisms of yeasts to exert their effects on the digestive processes of ruminants but it was also confirmed that the response to the inclusion of yeasts can vary due to multiple 
factors such as diet, species or strain used, dose and even the animal (Cagle et al 2019). For all the above, it is considered necessary to carefully select the microbial additives to be used, according to the specific characteristics of each production system.

Therefore, the objective of this research was to study the effect of the inclusion of yeasts from different species on the in vitro gas production of Tifton hay under Brazilian edaphoclimatic conditions.

\section{Material and Methods}

This study was carried out in the laboratories of Animal Nutrition (LANA) of the Nuclear Energy Center for Agriculture (CENA) from the University of Sao Paulo, Brazil. The in vitro gas production technique was used to compare the effect of the inclusion of yeasts of different species in the ruminal fermentation of Tifton hay. The treatments consisted of the inclusion of yeast culture at a rate of $7.5 \mathrm{mg}$ de DM. $\mathrm{mL}^{-1}$ (equivalent to $10 \mathrm{~g}$ de DM/animal) for being the amount that is generally included in ruminant diets. So, $3.5 \mathrm{~mL}$ of the yeast strain culture was added in each treatment according to DM results of the culture that was previously determined and the presence of living cells in they were among 6 and $15 \times 10^{7}$ cel. $\mathrm{mL}^{-1}$.

The yeast strains evaluated were: Strain A (Rhodotorula mucilaginosa), Strain B (Issatchenkia orientalis), Strain C (Candida tropicalis), Strain D (Pichia guilliermondii), Strain E (S. cerevisiae, FLEISHMANN), and Strain F (S. cerevisiae, $\mathrm{L} / 25 / 7 / 13)$. The first four belong to the Bank of Microorganisms from the Institute of Animal Science (Mayabeque, Cuba) with registration number 980 in the World Data Centre for Microorganisms (WDCM and its gene sequences are located in the Gen Bank (Marrero et al. 2013). The last two are used for alcohols production in Brazil and Cuba, respectively. In addition, a control was included where yeasts were not added and $3.5 \mathrm{~mL}$ of YPD medium was placed to eliminate the dilution factor. The substrate used was Tifton hay with DM at $100{ }^{\circ} \mathrm{C}$ of $904.99 \mathrm{~g} / \mathrm{Kg}$ of green matter, ash of 54.11 , organic matter of 945.11 the NDF of 851.07 , the ADF of 493.46, and lignin of 103.82 (values expressed in $\mathrm{g} / \mathrm{kg}$ of dry matter)

\section{Collection and preparation of rumen inoculum}

The inoculum was extracted from 5 Santa Ines sheep cannulated in rumen with an average weight of $60 \pm 2.5 \mathrm{~kg}$ that intake Tifton hay with free access to a mixture of water and minerals. $0.5 \mathrm{~g}$ of substrate was included in a culture medium and an inoculum of ruminal microorganisms at a ratio of 50:25 of the total incubation volume (25 mL of LRF + 50 of incubation medium $=75 \mathrm{~mL}$ ). For the preparation of the inoculum, the liquid and solid fractions of the ruminal content of each animal were separately collected. Then they were mixed at a rate of $50 \%$ of the solid material and $50 \%$ of the liquid in a blender for 5 seconds in order to release the cellulolytic microorganisms adhered to the fiber. The resulting material was filtered through 3 layers of gauze and kept in a water bath at $39^{\circ} \mathrm{C}$ with a constant flow of $\mathrm{CO}_{2}$.

\section{Determination of gas and methane production}

The determination of in vitro gas production was performed according to the Theodorou et al (1994) technique adapted to a semi-automatic system (Bueno et al. 2005) using a pressure transducer and data store (Pressure Press Data 800, LANA, CENA-USP, Piracicaba/ Sao Paulo). Incubations were carried out in glass bottles of $100 \mathrm{~mL}$ capacity sealed tightly with a butyl stopper. They were placed in a stove at a temperature of $39{ }^{\circ} \mathrm{C}$. Gas production was manually measured with the transducer at 4, 8, 12, and 24 hours after fermentation started. For each treatment, five repetitions (ruminal inoculums in different bottles) were used and six blank (bottles with inoculum, without yeast, and without substrate), and six bottles equal to the blank were placed, but the yeast culture was added.

For the measurement of CH4 using a gas chromatograph system (Shimadzu 2014, Chiyodaku, Tokyo, Japan), during each one of the pressure measurement events, $2.5 \mathrm{~mL}$ gas samples were collected from the bottles, using $5 \mathrm{~mL}$ syringes, and stored in $10 \mathrm{~mL}$ vacuum tubes, as described by Soltan et al (2012). Methane concentration was determined by external calibration with an analytical curve $(0,3,6,9$, and $12 \%)$ of pure gas (White Martins PRAXAIR gases Industrial INC, Osasco-SP, 99.5\% purity). Methane concentration was calculated according to Longo et al 2006 by the equation:

$$
\mathrm{CH} 4, \mathrm{~mL}=\text { (total gas, } \mathrm{mL}+, 85 \mathrm{~mL}) \times \mathrm{CH} 4 \%
$$




\section{Determination of the DM of yeast inoculums}

The DM of each yeast was first determined. For this, cultures in Petri dishes were used in YPD medium with agar with 24 hours of growth at $30^{\circ} \mathrm{C}$. Some Lops of these cultures were taken and inoculated in test tubes containing $5 \mathrm{~mL}$ of the same liquid medium until turbidity similar to the MacFarland 2 standard was achieved that was incubated under the same conditions. At 24 hours, $1 \mathrm{~mL}$ of this culture was taken and inoculated in $50 \mathrm{~mL}$ of YPD medium in an erlenmeyer of $200 \mathrm{~mL}$ capacity. These erlenmeyers were incubated at $30^{\circ} \mathrm{C}$ for 24 hours. From this culture, $20 \mathrm{~mL}$ was taken and centrifuged at $3000 \mathrm{rpm}$ and dried in an oven at $60^{\circ} \mathrm{C}$. The DM was determined by weight difference.

\section{Determination of ammoniacal nitrogen and protozoa count}

Ammoniacal nitrogen was determined by the micro-Kjeldahlj method (AOAC 1995). In this method samples containing up to $50 \mathrm{ug}$ nitrogen are digested in tubes with sodium selenite (in sulphuric-phosphoric mixture) plus hydrogen peroxide during one hour at $380^{\circ} \mathrm{C}$. Ammonium liberated is measured without extraction by Berthelot colorimetric reaction (Guebel et al 1991). The protozoa were counted directly in the Neubauer chamber microscope. For this, they were stained with a solution of gentian violet in $1 \%$ acetic acid.

\section{Mathematical analysis and design}

Analysis of variance was performed according to a completely randomized design with five repetitions for each treatment for the indicators of methane production, ammoniacal nitrogen, $\mathrm{pH}$, and protozoa count. For the results of cumulative gas production, the modeling of the curves was performed by the two-compartment model and the Gompertz model was fitted. Statistical criteria were taken into account: coefficient of determination, significance of the adjustment and parameters and normality of residues: $P G(a, b, c, t)=a^{*} \exp \left(-b^{*} \exp \left(-c^{*} t\right)\right)$

The comparison between the treatments was carried out in accordance with the methodology presented by Jay et al (2012) which consist of a test of homogeneity of regression curves using the Corrected Akaike Information Criterion. Then, the mean square distance of the fitted curves was taken as the basis for the post-hoc multiple comparison tests, using the minimum significant difference for a significance level $p<0.01$ as the tenth comparison. The experimental results were analyzed with the statistical package InfoStat version 1.0 (Balzarini et al 2012).

\section{Results and discussion}

Only the strains $I$. orientalis and S. cerevisiae $L / 25 / 7 / 13$ provided gas production values higher than the control, while strains $C$. tropicalis and $P$. guilliermondii were below, showing a depressing effect of the fermentation process of the substrate (figure 1). The strain $R$. mucilaginosa and $S$. cerevisiae, and FLEISHMANN provided a gas production equal to the control. The results of multiple comparisons of values of the production had a significance of $p<0.01$ (Table 1 ).

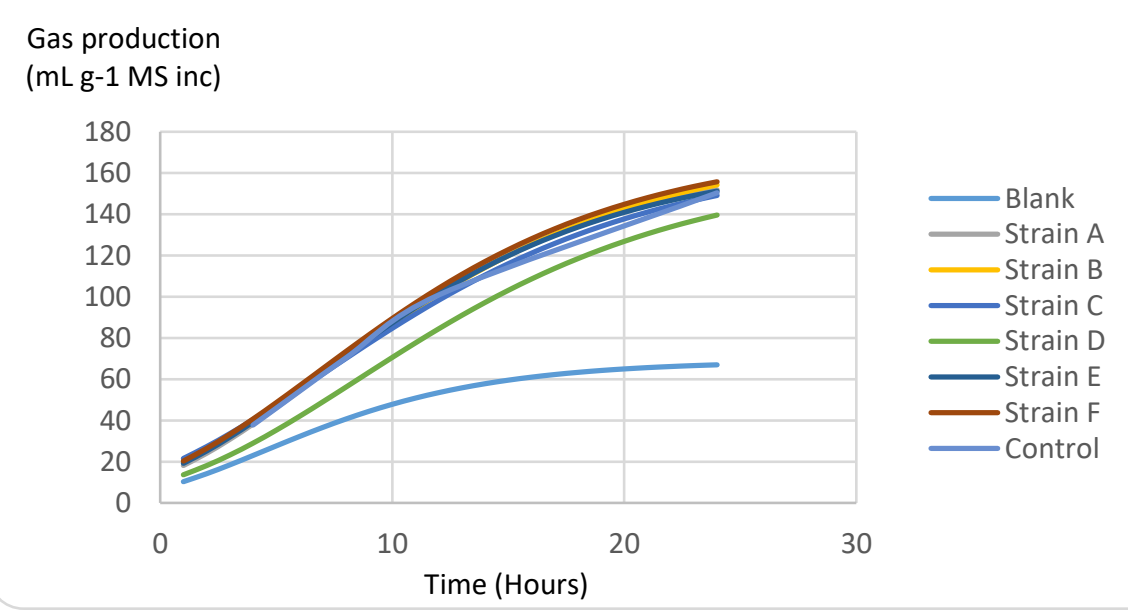

Figure 1 Cumulative gas production of Tifton hay with the inclusion of yeast strains of different species 
Table 1 Results of multiple comparisons of Tifton hay accumulated gas production values with the inclusion of yeast strains of different species.

\begin{tabular}{lc}
\hline Treatments & $\begin{array}{c}\text { Gas production values accumulated at } \\
24 \text { hours (mL/g DM) }\end{array}$ \\
\hline Blank & $66.98^{\mathrm{a}}$ \\
Control without yeast & $150.42^{\mathrm{b}}$ \\
Strain A (R. mucilaginosa) & $151.90^{\mathrm{bc}}$ \\
Strain B ( I. orientalis) & $154.29^{\mathrm{c}}$ \\
Strain C (C. tropicalis) & $149.13^{\mathrm{d}}$ \\
Strain D (P. guilliermondii) & $139.13^{\mathrm{e}}$ \\
Strain E (S. cerevisiae, FLEISHMANN) & $151.23^{\mathrm{bc}}$ \\
Strain F (S. cerevisiae, L/25/7/13) & $155.77^{\mathrm{f}}$ \\
\hline
\end{tabular}

*Different letters represent statistically significant differences $(P<0.01)$ LSD. EE 1.700.

Despite these results in gas production, the inclusion of yeasts had no influence on $\mathrm{pH}$, methane and ammonia nitrogen production or the rumen protozoan population (Table 2).

Table 2 Effect of yeast inclusion on $\mathrm{pH}$, concentration of $\mathrm{N}$-ammonia, methane and protozoan population.

\begin{tabular}{lcccc}
\hline Treatments & $\begin{array}{c}\text { N-ammonia } \\
\mathrm{mg} / 100 \mathrm{ML}\end{array}$ & $\mathrm{pH}$ & $\begin{array}{c}\text { Methane } \\
\mathrm{mL} / \mathrm{gDM}\end{array}$ & $\begin{array}{c}\text { Protozoan population } \\
\left(\times 10^{5} \mathrm{cel} \cdot \mathrm{mL}^{-1}\right)\end{array}$ \\
\hline Control without yeast & 43.40 & 6.77 & 10.95 & 8.67 \\
Strain A (R. mucilaginosa) & 41.44 & 6.79 & 11.87 & 8.07 \\
Strain B ( I. orientalis) & 42.56 & 6.78 & 11.87 & 7.71 \\
Strain C (C. tropicalis) & 41.72 & 6.76 & 11.01 & 8.19 \\
Strain D (P. guilliermondii) & 45.08 & 6.80 & 11.45 & 6.27 \\
Strain E (S. cerevisiae, FLEISHMANN) & 40.60 & 6.78 & 11.62 & 6.21 \\
Strain F (S. cerevisiae, L/25/7/13) & 44.80 & 6.79 & 10.85 & 8.79 \\
EE & 5.31 & 5.00 & 5.13 & 5.16 \\
\hline
\end{tabular}

It is important in the results of this study to observe that the two strains belonging to the $S$. cerevisiae species did not have the same effect on the gas production of the substrate. In this case, strain $L / 25 / 7 / 13$ is used in alcohol distillation processes in Cuba and FLEISHMANN is a strain that is marketed for the production of bread and sweets. In another research, Pszczolkowski et al (2016) studied the effect of lyophilized craft brewer's yeast and baker's yeast. They showed that yeasts are a rich source of protein and that brewer's yeast contains hops plant $\alpha$-y $\beta$-acids (Humulus lupulus $L$.) with additional potential benefit as a supplement since the amount of methane produced decreased in the rumen of cattle and goats. This corroborates that the effect of the strains that are used as additives on the ruminal microbial population is very specific.

Regarding the use of products with different strains of Saccharomyces cerevisiae, in concentrated diets, Cobos et al (2010) found diverse results where none of the yeast products studied modified the IVDMD of the diet and the $\mathrm{pH}$ of the incubated fluids but at 24 hours reduced lactic acid concentrations and increased the acetate: propionate relation. Also, two of the strains under study increased the population of ruminal microorganisms while the third did not modify it. These results corroborate the importance of selecting the appropriate strain according to the used diet.

As showed in this study, other strains other than Saccharomyces could be used as an additive for ruminant diets. Ruiz et al (2016) studied, under in vitro conditions for 24 hours, the action of a strain of Candida norvegensis yeast in the ruminal fermentation of oat straw and obtained increases in ruminal fermentation parameters, as well as microbial growth with reduction of methane production. In addition, the yeast inoculum also improved IVDMD and the concentration of ammonia-N.

On the other hand, Wang et al (2016) compared the effects of the addition of three different species of live yeast (Candida utilis, Saccharomyces cerevisiae and Candida tropicalis) with four doses $\left(0,0.25 \times 10^{7}, 0.50 \times 10^{7}\right.$, and $0.75 \times$ 
$10^{7}$ colony forming unit [cfu]) on the kinetics of in vitro gas production and fermentation parameters of corn and rice straw. They concluded that $C$. tropicalis was the strain of best results as an additive and its optimal dose should be 0.25 $\times 10^{7} \mathrm{cfu} / 500 \mathrm{mg}$ of substrates in vitro. Nooraee et al (2010) also demonstrated that Kluyveromyces marxianus increased the digestibility of in vitro dry material of alfalfa, guinea grass, and timothy hay by ruminal microorganisms.

Another aspect that attracts attention is the depressing effect that $P$. guilliermondii strain exerted on the fermentation of Tifton hay since in previous studies, Marrero et al (2020) found that the same dose of this strain stimulated the production of Cynodon gas nlemfuensis, which also constitutes a fibrous substrate, although the ruminal inoculum used came from adult cattle. Regarding this, Tesfaye and Hailu (2019) stressed that there are several factors that can influence the effect of microbial additives, among which are: the animal species, their physiological conditions, the type of diet, the dose of the additive, the strain, among others.

\section{Conclusions}

Strains I. orientalis and S. cereviasiae L / 25/7/13 stimulated the gas production by ruminal microorganisms when Tifton hay was fermented. However, there were no differences in the production of ammoniacal nitrogen and methane or in the protozoan population of the rumen with respect to the control.

The determining effect of diet, species, strain and culture medium of yeasts in ruminal fermentation is confirmed, which states the importance of selecting the appropriate strains to be used as additive in ruminant diets, in accordance with the food to be use.

\section{Conflict of Interest}

The authors declare no conflict of interest.

\section{Funding}

This research was carried out through funding by CAPES.

\section{References}

AOAC. Official Method of analysis (1995) 16th Ed. Ass. Off. Agric. Chem. Washington, D.C.

Al Ibrahim RM, Gath VP, Campion DP, McCarney C, Duffy P, Mulligan FJ (2012) The effect of abrupt or gradual introduction to pasture after calving and supplementation with $S$. cerevisiae (Strain 1026) on ruminal pH and fermentation in early lactation dairy cows. Animal Feed Science and Technology 178:40-47

Balzarini, G M, Casanoves F, Di Rienzo, J A, González L A and Robledo C W (2012) InfoStad. Software estadístico. Manual del usuario. Versión 1. 0. Córdoba, Argentina.

Bruno RGS, Rutigliano HM, Cerri RL, Robinson PH, Santos JEP (2009) Effect of feeding S. cerevisiae on performance of dairy cows during summer heat stress. Animal Feed Science and Technology 150:175-186

Bueno IQS, Filho SLS, Gobbo SP, Louvandini H, Vitti DMSS, Abdall AL (2005) Influence of inoculum source in gas production method. Animal Feed Science and Technology. DOI: 10.1016/j.anifeedsci.2005.05.003

Cagle CM, Fonseca MA, Todd R. Callaway TR, Runyan CA, Cravey MD, Tedeschi LO (2019) Evaluation of the effects of live yeast on rumen parameters and in situ digestibility of dry matter and neutral detergent fiber in beef cattle fed growing and finishing diets Applied Animal Science. DOI: 10.15232/aas.2019-01888

Castillo Y, Ruiz O, Burrola M E, Marrero Y, Salinas J, Angulo, C, Corral A, Arzola C, Itza M and Camarillo J (2016) Isolation and characterization of yeasts from fermented apple bagasse as additives for ruminant feeding. Brazilian Journal of Microbiology 47:889895 .

Chaucheyras F, Chevaux E, Martin C, Forano E (2012) Use of Yeast Probiotics in Ruminants: Effects and mechanisms of action on rumen $\mathrm{pH}$, fibre degradation, and microbiota according to the diet, Chapter 7. IntechOpen. DOI: 10.5772/50192

Cobos MA, Valencia LH, Pinos JM, González SS, Ramírez J, Hernández D (2010) Influence of yeast products on rumen microorganisms, in vitro degradation and fermentation of a diet for steers. J. Appl. Anim. DOI: 10.1080/09712119.2010.9707111

Elghandour MMY, Salem AZM, Martínez JS, Camacho LM, Kholif A,Vázquez JC (2014) Direct Fed Microbes: A Tool for Improving the Utilization of Low Quality Roughages in Ruminants. Journal of Integrative Agriculture. DOI: 10.1016/S2095-3119(14)60834-0 
Guebel DV, Nubel CB, Giulietti AM (1991) A simple and rapid micro-Kjeldahl method for total nitrogen analysis. Biotechnology Techniques. DOI: 10.1007/BF00155487

Jay O, Torres V, Marrero Y and Torres JP (2012) Sensibility analysis of homogencity tests of in vitro gas production curves by Monte Carlo simulation. Cuban Journal of Agricultural Science 46:15-22 .

Jay O, Torres V, Marrero Y and Torres JP (2012) Tests assessements for multiple comparisons of in vitro gas curves from the root of the mean square distance. Cuban Journal of Agricultural Science 46:133.

Longo C, Bueno ICS, Nozella EF, Goddoy PB, Abral Filho SLS, Abdalla AL (2006) The influence of head-space and inoculum dilution on in vitro ruminal methane measurements. International Congress Series. DOI: 10.1016/j.ics.2006.03.017

Marrero Y, Galindo J, Castillo Y, Ruiz O (2020) Development of yeast additives for feeding ruminants in Cuba. Cuban Journal of Agricultural Science 54:457-469.

Marrero Y, Rodríguez R, Torres V, Jay O, Galindo, J (2020) Efecto de las levaduras en la producción de gas de Cynodon nlemfuensis en una incubación ruminal in vitro. Livestock Research for Rural Development 32:1.

Nooraee SE, Alimon AR, Ho YW, Abdullah N (2010) Characterization of Kluyveromyces marxianus as a potential feed additive for ruminants. Letters in Applied Microbiology 50:547-656.

Pszczolkowski VL, Bryant RW, Harlow BE, Aiken GE, Martin LJ, Flythe MD (2016) Effects of Spent Craft Brewers' Yeast on Fermentation and Methane Production by Rumen Microorganisms. Advances in Microbiology 6:716-723.

Ruiz O, Castillo Y, Arzol, C, Burrola E, Salinas J, Corral A, Hume ME, Murillo M, Itza M (2016) Effects of Candida norvegensis Live Cells on In vitro Oat Straw Rumen Fermentation. Asian-Australas J. Anim. Sci. DOI:10.5713/ajas.15.0166

Soltan YA, Morsy AS, Sallam SMA, Louvandini H, Abdalla AL (2012) Comparative in vitro evaluation of forage legumes (prosopis, acacia, atriplex, and leucaena) on ruminal fermentation and methanogenesis. Journal of Animal and Feed Sciences 21:759-772.

Tesfaye A, Hailu Y (2019) The effects of probiotics supplementation on milk yield and composition of lactating dairy cows. The Journal of Phytopharmacology 8:12-17.

Theodorou MK, Williams BA, Dhanoa MS, McAllan ADB, France J (1994) A simple gas production method using a pressure transducer to determine the fermentation kinetics of ruminant feeds, Animal Feed Science and Technology 48:185 .

Tripathim K, Karims A (2010) Effect of individual and mixed live yeast culture feeding on growth performance, nutrient utilization and microbial crude protein synthesis in lambs. Animal Feed Science and Technology 155:163-171.

Wang Z, He Z, Beauchemin KA, Tang S, Zhou C, Han X, Wang M, Kang J, Odongo NE, Tan Z (2016) Evaluation of different yeast species for improving in vitro fermentation of cereal straws. Asian-Australas J. Anim. Sci. 29:230-240. 